ISSN 1983-8484

Licenciado sob uma Licença Creative Commons

\title{
Avaliação de recursos estratégicos em empresas hoteleiras de um município sul-mato-grossense ${ }^{1}$
}

\author{
Evaluation of strategic resources in hospitality companies of a Brazilian city
}

Luciano Costa Santos $^{[a]}$, Cláudia Fabiana Gohr ${ }^{[b]}$, Igor Kenji Hilahata Cruz ${ }^{[c]}$

[a] Doutor em Engenharia de Produção pela Universidade Federal de Santa Catarina (UFSC), professor do Departamento de Engenharia de Produção da Universidade Federal da Paraíba (UFPB), João Pessoa, PB - Brasil, e-mail: luciano@ct.ufpb.br

[b] Doutora em Engenharia de Produção pela Universidade Federal de Santa Catarina (UFSC), professora do Departamento de Engenharia de Produção da Universidade Federal da Paraíba (UFPB), João Pessoa, PB - Brasil, e-mail: claudiagohr@ct.ufpb.br

[c] Engenheiro de Produção pela Universidade Federal da Grande Dourados (UFGD), Dourados, MS - Brasil, e-mail: igor_kc88@hotmail.com

\section{Resumo}

Embora a visão baseada em recursos represente uma das principais correntes de pensamento da área de estratégia empresarial, a identificação e a análise de recursos é uma atividade de difícil operacionalização e ainda pouco estudada. Reconhecendo a importância dessa atividade e contribuindo com um procedimento metodológico para a avaliação de recursos, este trabalho tem como objetivo identificar e analisar os recursos estratégicos de empresas pertencentes ao setor hoteleiro de um município do estado de Mato Grosso do Sul com um elevado fluxo de turistas de negócios. Para alcançar esse objetivo, foram realizados estudos de casos em dois hotéis, utilizando como técnica principal de coleta de dados a entrevista semiestruturada com perguntas abertas e fechadas dirigidas aos gerentes das empresas. Trata-se de uma pesquisa aplicada e de caráter descritivo que adotou uma abordagem predominantemente qualitativa para a análise de dados. Os resultados demonstraram a aplicabilidade da metodologia proposta e permitiram que os gerentes dos hotéis pesquisados tivessem condições de reconhecer seus recursos estratégicos e entender como poderiam melhorar o valor, a sustentabilidade e a versatilidade deles.

Palavras-chave: Recursos estratégicos. Gestão estratégica. Setor hoteleiro.

\footnotetext{
Abstract

Although resource-based view represents one of the main schools of thought in the field of business strategy, the identification and the analysis of resources is an activity difficult to implement and poorly studied. Recognizing the importance of this activity and contributing with a methodological procedure for the evaluation of resources,

1 Artigo publicado anteriormente no XVIII Simpósio de Engenharia de Produção (SIMPEP 2011) sob o título "Identificação e análise de recursos estratégicos em empresas do setor hoteleiro de um município do Estado de Mato Grosso do Sul".
} 
this study aims to identify and analyze strategic resources in companies of the hospitality industry in a city of Mato Grosso do Sul with a high flow of business tourists. To achieve this goal, we conducted case studies in two hotels, using as the main technique of data collection the semi-structured interview with open and closed questions directed to the managers. It is an applied and descriptive research which adopted a predominantly qualitative approach to data analysis. The results demonstrated the applicability of the proposed methodology and allowed the hotel managers to be able to recognize their strategic resources and to understand how they could improve the value, the sustainability and the versatility of them.

Keywords: Strategic resources. Strategic management. Hospitality industry.

\section{Introdução}

A visão baseada em recursos representa atualmente uma das correntes de pensamento mais importantes da área de estratégia empresarial. Essa corrente destaca o papel dos recursos empresariais na construção de uma vantagem competitiva sustentável. Por essa perspectiva, a estratégia empresarial é guiada de "dentro para fora", tendo como objetivos principais o desenvolvimento e a aquisição de recursos que serão responsáveis por formar a competência essencial da organização.

Entretanto, a despeito da importância do tema, a visão baseada em recursos ainda demonstra dificuldades para sua implementação prática. Para incorporar a visão baseada em recursos nos processos de formulação estratégica das empresas, é necessário que as mesmas utilizem instrumentos adequados para identificar e avaliar recursos estratégicos. Embora a clássica abordagem SWOT chame a atenção das empresas para conhecer seu ambiente interno, frequentemente as organizações se contentam com uma análise superficial de seus pontos fortes e fracos, sem uma atenção maior para o desenvolvimento de recursos que podem compor um diferencial competitivo no mercado.

Procurando reforçar a importância da visão baseada em recursos e contribuindo com um procedimento metodológico para a avaliação de recursos estratégicos, este artigo apresenta um estudo feito em dois hotéis de um município do Estado de Mato Grosso do Sul com um elevado fluxo de turistas de negócios. Esse estudo teve o objetivo de identificar e analisar os recursos estratégicos das duas empresas, de modo a servir de base para futuros processos de formulação de estratégias. Os dois hotéis foram escolhidos em função de sua importância econômica e relevância para a cidade, demonstrada pela parcela representativa que possuem na participação de mercado. Além disso, o setor hoteleiro da região tem passado por uma fase de franca expansão e entrada de novos concorrentes. Em reação, as duas empresas reformaram suas instalações recentemente, o que denota uma preocupação com a sobrevivência no mercado em que atuam.

A estrutura do artigo inclui uma breve revisão de literatura sobre a visão baseada em recursos e seus pressupostos teóricos. Posteriormente, são relatados os procedimentos metodológicos que guiaram a coleta e a análise dos dados necessários para a realização da pesquisa de campo. Em seguida, os dois estudos de caso são apresentados conjuntamente, demonstrando os resultados da análise de seus recursos estratégicos. 0 texto segue com as discussões adicionais sobre os resultados e as considerações finais sobre o trabalho realizado.

\section{A estratégia segundo a visão baseada em recursos}

Um pensamento aceito na área de estratégia empresarial é que a vantagem competitiva de uma empresa depende das estratégias que a mesma adota e a manutenção dessa vantagem está baseada em seu processo de criação de valor. De acordo com Besanko et al. (2006), há duas formas pelas quais as organizações podem criar mais valor do que outras empresas do setor: (a) organizando a cadeia de valor diferentemente dos rivais; e (b) configurando a cadeia de valor de modo semelhante aos rivais, mas desenvolvendo atividades mais eficientemente, isto é, desenvolvendo recursos e competências que os concorrentes carecem.

Nesse sentido, os recursos da organização são considerados essenciais para a definição da estratégia e também para a garantia de sua vantagem competitiva, sendo este o pressuposto básico da visão baseada em recursos (RBV - Resource Based View). A RBV tem 
emergido como uma teoria promissora para analisar os recursos e a forma que estes permitem a sustentação da vantagem competitiva (BARNEY, 2001; MEDCOF, 2001). Segundo a RBV, a vantagem competitiva, medida como rentabilidade econômica, pode ser derivada de recursos estratégicos raros, difíceis de serem copiados e valiosos. Barney (2001) define recursos como todos os ativos, capacidades, processos organizacionais, atributos da firma, informação e conhecimento que são controlados pela firma e que a habilitam a conceber e a implementar estratégias eficientes. $\mathrm{O}$ autor propõe duas generalizações que são importantes para a RBV: (i) os recursos são distribuídos heterogeneamente através das firmas; e (ii) os recursos não podem ser transferidos sem custos.

0 conceito de recurso estratégico leva ao conceito de competência, um dos pilares da RBV. De acordo com Lewis (2003), as competências são formadas a partir de uma combinação de recursos e processos. Nesse caso, o termo "processos" tem um significado análogo ao de "rotinas", elemento que tem sido apontado como a fonte para a formação de competências (PENG; SCHROEDER; SHAH, 2008). Além disso, essa noção é complementada pela contribuição de Mills et al. (2002), que afirmam que essa combinação deve estar coordenada entre si, ou seja, não basta ter os recursos e os processos adequados, mas o modo que eles interagem é o que vai constituir uma competência. Aqui o conceito de coordenação tem uma relação direta com o conceito de configuração de recursos e competências apresentado por Gruber et al. (2010).

Porém, como a visão baseada em recursos poderia ser utilizada de maneira prática pelas organizações? Em busca de uma resposta a essa questão, Grant (1991) defendeu que fosse adotada uma abordagem baseada em recursos (RBV) para a formulação da estratégia empresarial e sugeriu um modelo de análise estratégica fundamentado nesse princípio. De fato, a antiga preocupação com a aplicação prática da RBV continua sendo uma temática atual e pode ser observada em trabalhos recentes na área de estratégia empresarial, como os de Arend e Lévesque (2010) e Kunc e Morecroft (2010).

É possível encontrar na literatura alguns estudos que tiveram o objetivo de identificação e análise de recursos e competências. Lewis (2003), por exemplo, realizou uma pesquisa para a análise de competências em três empresas do setor aeroespacial, na qual utilizou entrevistas semiestruturadas como a principal fonte de dados. De modo semelhante, Wong e Karia (2010), Escrig-Tena e Bou-Llusar (2005), Pandža et al. (2003) e Coates e McDermott (2002) também desenvolveram pesquisas relevantes para identificar e analisar competências e recursos estratégicos. No entanto, embora essas pesquisas tenham sido originais do ponto de vista de sua contribuição científica, nenhuma delas contribuiu com uma metodologia prática que pudesse ser utilizada pelas organizações em seus procedimentos de formulação da estratégia.

Nesse sentido, Nieweglowski, Lima e Costa (2010), Yang et al. (2006) e Mills, Platts e Bourne (2003) propuseram metodologias práticas que foram além das pesquisas usuais sobre a aplicação da RBV no processo de formulação estratégica. No trabalho de Nieweglowski, Lima e Costa (2010), os autores incorporaram a análise de competências ao método tradicional de avaliação de projetos de investimento. Já Yang et al. (2006) estabeleceram um modelo para identificar competências essenciais operacionalizado por meio de uma aplicação computacional, porém com o foco principal em competências humanas. Mills, Platts e Bourne (2003), por sua vez, desenvolveram uma metodologia de análise de recursos e competências que demonstrou sua aplicabilidade e integração com os procedimentos formais de formulação da estratégia. Um dos diferenciais da metodologia desses autores é que ela inclui um procedimento de avaliação do grau de importância de cada recurso.

Para a identificação dos recursos estratégicos de uma organização, sugere-se a categorização dos mesmos, de forma que o procedimento de análise seja guiado por uma espécie de check-list feito por categoria de recursos. De acordo com Mills et al. (2002), entender as categorias a que os recursos pertencem é importante por dois motivos:

a) para que posteriormente a descrição dos recursos seja mais compreensível para aquelas pessoas que não estiveram envolvidas no processo de identificação;

b) para garantir que nenhuma categoria de recursos deixe de ser considerada na análise.

Uma maneira mais abrangente para categorizar os recursos é dividindo-os em recursos tangíveis e recursos intangíveis. Essa divisão é amplamente reconhecida na literatura de estratégia empresarial, desde os clássicos trabalhos que fundamentam a visão baseada em recursos (RBV), tais como os de Penrose (1968) e de Wernerfelt (1984), até os trabalhos mais recentes na área, tais como o de Gruber et al. 
(2010). Esses dois tipos de recursos são definidos do seguinte modo:

a) recursos tangíveis: são aqueles recursos mais facilmente observáveis que geralmente incluem recursos físicos e humanos;

b) recursos intangíveis: são mais difíceis de identificar e quantificar e normalmente incluem recursos relacionados ao conhecimento organizacional.

Entretanto, o que caracteriza a importância de cada recurso em relação à sua contribuição para a vantagem competitiva de uma organização? Barney e Hesterly (2007) consideram que um recurso é estratégico quando ele consegue atender a quatro requisitos básicos (constituindo o que os autores denominaram de "modelo VRIO"): valor, raridade, inimitabilidade e organização, sendo este último requisito relacionado ao esforço da empresa para coordenar políticas e processos para tirar proveito desse recurso. Devido à sua relevância e praticidade, o modelo VRIO tem servido de framework para diversas pesquisas na área, como se pode observar, por exemplo, na pesquisa de Arend e Lévesque (2010).

Com uma abordagem similar à do modelo VRIO, Mills et al. (2002) estabelecem três critérios análogos: valor, sustentabilidade e versatilidade. De certa forma, esses requisitos são coerentes com os critérios definidos por autores tradicionais da área de estratégia empresarial, tais como Peteraf (1993) e Prahalad e Hamel (1990). 0 Quadro 1 apresenta o significado de cada um dos três critérios de avaliação de recursos sugeridos por Mills et al. (2002).

Os critérios de avaliação de recursos apresentados no Quadro 1 forneceram parâmetros essenciais para a pesquisa de campo, conforme será abordado na próxima seção.

\section{Procedimentos metodológicos}

A pesquisa relatada neste artigo se propôs a identificar e analisar os recursos estratégicos de duas empresas do setor hoteleiro de um município do

Quadro 1 - Critérios de avaliação de recursos

\begin{tabular}{|c|c|}
\hline Critérios & Significado \\
\hline Valor & $\begin{array}{l}\text { Um recurso é considerado valioso quando contribui consideravelmente para o } \\
\text { valor percebido pelo cliente, gerando um incremento na lucratividade como conse- } \\
\text { quência. Um recurso valioso é aquele que confere uma vantagem competitiva para } \\
\text { a empresa, possibilitando aproveitar oportunidades e afastar ameaças. Recursos } \\
\text { raros ou escassos tendem a ter um valor maior. }\end{array}$ \\
\hline Sustentabilidade & $\begin{array}{l}\text { Um recurso é sustentável quando seu valor pode ser mantido ao longo do tempo. } \\
\text { Para ser sustentável, o recurso deve ser de difícil imitação, seja pelo fato de os con- } \\
\text { correntes não o reconhecerem ou por ele ter sido desenvolvido em circunstâncias } \\
\text { específicas da história da organização. A sustentabilidade também é aumentada } \\
\text { pela sua dificuldade de substituição por outros recursos, sendo que a situação ide- } \\
\text { al seria quando nenhum outro recurso conseguisse garantir as mesmas vantagens } \\
\text { competitivas que ele garante. }\end{array}$ \\
\hline Versatilidade & $\begin{array}{l}\text { Um recurso versátil pode ser transferido para outros produtos e mercados, ou mes- } \\
\text { mo, para outros negócios. Parte da premissa de que o conhecimento contido em um } \\
\text { recurso pode ser utilizado de outras maneiras que vão além de sua aplicação atual } \\
\text { e que podem ser igualmente vantajosas. Um recurso versátil não depende muito de } \\
\text { outros recursos complementares, não está vinculado a nenhuma região geográfica } \\
\text { e também não necessita de muito tempo para ser transferido. Outro fator que con- } \\
\text { tribui para aumentar a versatilidade é o grau de conhecimento explícito que se tem } \\
\text { sobre o recurso, seja documentado ou codificado de outras formas. }\end{array}$ \\
\hline
\end{tabular}

Fonte: Baseado em MILLS et al., 2002. 
Estado de Mato Grosso do Sul. Como os conceitos da visão baseada em recursos eram desconhecidos nas empresas investigadas, foi necessário adotar um método de pesquisa que permitisse uma análise em profundidade para explicitar informações que ainda não eram bem compreendidas. Por esse motivo foi escolhido o método do estudo de caso, defendido por Yin (1994) em situações que se deseja uma compreensão mais profunda sobre o real contexto do objeto pesquisado. Foi conduzida uma pesquisa de natureza aplicada e de caráter descritivo, utilizando método do estudo de caso como estrutura procedimental para o delineamento da pesquisa de campo.

A principal técnica de coleta de dados para a condução dos estudos de caso foi a entrevista semiestruturada, com perguntas abertas e fechadas dirigidas aos proprietários dos hotéis pesquisados no primeiro semestre de 2011. Em paralelo, foi feito o uso da observação passiva realizada durante a aplicação das entrevistas, de forma que os elementos observados pudessem confirmar ou desencadear novas perguntas abertas para as entrevistas.

As perguntas abertas previstas no roteiro de entrevista tiveram o objetivo de identificar a estratégia utilizada pelas empresas e, a partir daí, favorecer a identificação dos recursos que suportavam essa estratégia. Para a identificação dos recursos estratégicos, eram apresentadas aos entrevistados as categorias de recursos apresentadas no Quadro 2, que foram baseadas nas propostas de Mills et al. (2002), Slack e Lewis (2009) e Armistead e Clark (1993). Durante as entrevistas, as categorias de recursos serviam como uma espécie de check-list que auxiliava na identificação dos recursos estratégicos.

As perguntas fechadas que constavam no roteiro de entrevista estavam relacionadas com a avaliação dos recursos identificados. No entanto, embora houvesse cinco alternativas de resposta para cada item avaliado, cada questão deveria ser conduzida pela entrevista, o que a diferenciava de um questionário estruturado que pode ser aplicado sem a presença do pesquisador. Para serem respondidas, as questões necessitavam de reflexão por parte do entrevistado e de esclarecimentos adicionais por parte dos pesquisadores. À medida que se obtinha uma resposta definitiva, os resultados eram assinalados em planilhas de avaliação de recursos, tal como mostram os Quadros 3, 4 e 5.

Em relação aos formulários de avaliação de recursos propostos por Mills et al. (2002), os modelos de avaliação apresentados nos Quadros 3, 4 e 5 contribuem com a atribuição de uma pontuação

Quadro 2 - Categorias de recursos estratégicos adotadas na pesquisa de campo

\begin{tabular}{|c|c|c|}
\hline \multicolumn{2}{|c|}{ Categorias de recursos } & \multirow{2}{*}{$\begin{array}{l}\text { Descrição } \\
\text { Estrutura física da empresa. Inclui diversos elementos, tais como, máquinas, equipamentos, } \\
\text { construções, decoração interna, localização, etc. }\end{array}$} \\
\hline \multirow{4}{*}{ Tangíveis } & Instalações & \\
\hline & Pessoal & $\begin{array}{l}\text { Recursos humanos responsáveis por executar, manter e gerenciar as empresas. Incluem } \\
\text { funcionários e gerentes em todos os níveis. }\end{array}$ \\
\hline & Clientes & $\begin{array}{l}\text { Clientes externos que são os destinatários dos produtos. Em serviços, por exemplo, o cliente } \\
\text { pode ser considerado como um recurso, pois é parte integrante do sistema de operações. }\end{array}$ \\
\hline & Materiais & $\begin{array}{l}\text { Bens consumidos no processo ou oferecidos como parte do pacote de valor. Incluem materiais } \\
\text { que são transformados pelo processo, advindos do cliente ou de fornecedores externos. }\end{array}$ \\
\hline \multirow{4}{*}{ Intangíveis } & Informações & $\begin{array}{l}\text { Recursos informacionais que podem vir dos clientes e de outras fontes do ambiente externo } \\
\text { ou interno (ex.: banco de dados de clientes, informações confidenciais do mercado, etc.). }\end{array}$ \\
\hline & Sistemas & $\begin{array}{l}\text { Rotinas e procedimentos que podem ser documentados ou não, e que dependem de conhe- } \\
\text { cimento, habilidades e informações para funcionar (ex.: software, certificações ISO, etc.). }\end{array}$ \\
\hline & Experiência & $\begin{array}{l}\text { Conhecimento tácito, não documentado na forma de sistemas, que foi desenvolvido ao } \\
\text { longo do tempo. Inclui também a cultura e os valores da organização. }\end{array}$ \\
\hline & Relacionamento & $\begin{array}{l}\text { Relação com todos os grupos de interesse (stakeholders) e reputação da empresa no merca- } \\
\text { do. Inclui parcerias e alianças estratégicas, relações com o governo, redes informais, etc. }\end{array}$ \\
\hline
\end{tabular}

Fonte: Dados da pesquisa. 
Quadro 3 - Modelo de avaliação do valor do recurso

\begin{tabular}{|c|c|c|c|c|c|}
\hline \multirow{2}{*}{ Valor do Recurso } & \multicolumn{5}{|c|}{ Pontuação } \\
\hline & 1 & 2 & 3 & 4 & 5 \\
\hline $\begin{array}{l}\text { Qual é o seu efeito sobre a lucratividade da } \\
\text { organização? }\end{array}$ & $\begin{array}{l}\text { Altamente } \\
\text { negativo }\end{array}$ & $\begin{array}{l}\text { Impacto } \\
\text { negativo }\end{array}$ & $\begin{array}{l}\text { Impacto } \\
\text { nulo }\end{array}$ & $\begin{array}{l}\text { Impacto } \\
\text { positivo }\end{array}$ & $\begin{array}{l}\text { Altamente } \\
\text { positivo }\end{array}$ \\
\hline $\begin{array}{l}\text { Qual é a sua influência para ajudar a empresa a não } \\
\text { ter uma desvantagem competitiva? }\end{array}$ & $\begin{array}{l}\text { Altamente } \\
\text { negativo }\end{array}$ & $\begin{array}{l}\text { Impacto } \\
\text { negativo }\end{array}$ & $\begin{array}{l}\text { Impacto } \\
\text { nulo }\end{array}$ & $\begin{array}{l}\text { Impacto } \\
\text { positivo }\end{array}$ & $\begin{array}{l}\text { Altamente } \\
\text { positivo }\end{array}$ \\
\hline $\begin{array}{l}\text { Qual é a sua influência para ajudar a empresa a } \\
\text { obter uma vantagem competitiva? }\end{array}$ & $\begin{array}{l}\text { Altamente } \\
\text { negativo }\end{array}$ & $\begin{array}{l}\text { Impacto } \\
\text { negativo }\end{array}$ & $\begin{array}{l}\text { Impacto } \\
\text { nulo }\end{array}$ & $\begin{array}{l}\text { Impacto } \\
\text { positivo }\end{array}$ & $\begin{array}{l}\text { Altamente } \\
\text { positivo }\end{array}$ \\
\hline Quantos concorrentes já possuem o mesmo recurso? & Todos & A maioria & Metade & Alguns & Nenhum \\
\hline $\begin{array}{l}\text { Comparado com a concorrência, qual o nível de } \\
\text { qualidade desse recurso? }\end{array}$ & $\begin{array}{l}\text { Muito abai- } \\
\text { xo da média } \\
\text { do setor }\end{array}$ & $\begin{array}{l}\text { Abaixo da } \\
\text { média do } \\
\text { setor }\end{array}$ & $\begin{array}{l}\text { Na média } \\
\text { do setor }\end{array}$ & $\begin{array}{l}\text { No nível dos } \\
\text { melhores }\end{array}$ & $\begin{array}{l}\text { Liderança } \\
\text { inquestio- } \\
\text { nável }\end{array}$ \\
\hline
\end{tabular}

Fonte: Adaptado de MILLS et al., 2002.

Quadro 4 - Modelo de avaliação da sustentabilidade do recurso

\begin{tabular}{|c|c|c|c|c|c|}
\hline \multirow{2}{*}{ Sustentabilidade do Recurso } & \multicolumn{5}{|c|}{ Pontuação } \\
\hline & 1 & 2 & 3 & 4 & 5 \\
\hline $\begin{array}{l}\text { Com que facilidade os concorrentes podem adquirir } \\
\text { este recurso? }\end{array}$ & $\begin{array}{l}\text { Muito facil- } \\
\text { mente }\end{array}$ & $\begin{array}{l}\text { Com certa } \\
\text { facilidade }\end{array}$ & $\begin{array}{l}\text { Com certa } \\
\text { dificuldade }\end{array}$ & Dificilmente & $\begin{array}{l}\text { O recurso é } \\
\text { único }\end{array}$ \\
\hline $\begin{array}{l}\text { Quanto tempo demora para se obter um retorno } \\
\text { financeiro sobre este recurso? }\end{array}$ & $<1$ mês & $\begin{array}{l}1-6 \\
\text { meses }\end{array}$ & $\begin{array}{l}6 \text { - } 24 \\
\text { meses }\end{array}$ & $\begin{array}{l}2-5 \\
\text { anos }\end{array}$ & $>5$ anos \\
\hline $\begin{array}{l}\text { Qual seria o percentual de faturamento para adqui- } \\
\text { rir tal recurso? }\end{array}$ & $<0,5 \%$ & $0,5-1 \%$ & $1-5 \%$ & $5-20 \%$ & $>20 \%$ \\
\hline Qual a taxa de depreciação desse recurso? & $>50 \%$ ano & $30-50 \%$ & $15-30 \%$ & $5-15 \%$ & $<5 \%$ \\
\hline $\begin{array}{l}\text { Sua vantagem pode ser substituída por outro } \\
\text { recurso? }\end{array}$ & $\begin{array}{l}\text { Completa- } \\
\text { mente }\end{array}$ & $\begin{array}{l}\text { Em grande } \\
\text { parte }\end{array}$ & Parcialmente & Dificilmente & $\begin{array}{l}\text { De forma } \\
\text { alguma }\end{array}$ \\
\hline
\end{tabular}

Fonte: Adaptado de MILLS et al., 2002.

para cada item avaliado. Assim, é possível obter um valor numérico que dá a noção quantificável do grau de importância de cada recurso. Essa noção é dada pelo somatório de pontos das questões relacionadas a cada critério de valor, sustentabilidade e versatilidade.

Em algumas situações, pode acontecer de existirem questões que não são aplicáveis. Nesse caso, a questão não aplicável não deve ser considerada na pontuação total do critério, que é calculada utilizando apenas as questões válidas. Desse modo, a pontuação total se dá pela proporcionalidade das questões válidas, tal como mostra a fórmula abaixo:

De acordo com a escala que foi definida, a pontuação total do recurso variará de 5 a 25 pontos. A partir desse intervalo, foram estabelecidos cinco diferentes níveis que denotam a intensidade do recurso avaliado: muito baixo ( 5 a 8 pontos), baixo ( 9 a 12 pontos), médio (13 a 17 pontos), alto (18 a 21 pontos) e muito alto ( 22 a 25 pontos). É importante destacar que as pontuações se apresentam em números inteiros e, caso haja uma pontuação com 
Quadro 5 - Modelo de avaliação da versatilidade do recurso

\begin{tabular}{|c|c|c|c|c|c|}
\hline \multirow{2}{*}{ Versatilidade do Recurso } & \multicolumn{5}{|c|}{ Pontuação } \\
\hline & 1 & 2 & 3 & 4 & 5 \\
\hline $\begin{array}{l}\text { O recurso pode ser transferido para outros serviços } \\
\text { e unidades da empresa? }\end{array}$ & Impossível & $\begin{array}{l}\text { Com dificul- } \\
\text { dade }\end{array}$ & $\begin{array}{l}\text { Com algum } \\
\text { esforço }\end{array}$ & Facilmente & $\begin{array}{l}\text { Muito facil- } \\
\text { mente }\end{array}$ \\
\hline $\begin{array}{l}\text { Este recurso depende de recursos e/ou processos } \\
\text { complementares para ser transferido? }\end{array}$ & $\begin{array}{l}\text { Completa- } \\
\text {-mente }\end{array}$ & $\begin{array}{l}\text { Depende } \\
\text { bastante }\end{array}$ & $\begin{array}{l}\text { Parcialmen- } \\
\text { te }\end{array}$ & $\begin{array}{l}\text { Depende } \\
\text { pouco }\end{array}$ & $\begin{array}{l}\text { Indepen- } \\
\text { dente }\end{array}$ \\
\hline $\begin{array}{l}\text { Este recurso está vinculado a alguma região geo- } \\
\text { gráfica? }\end{array}$ & $\begin{array}{l}\text { Vínculo } \\
\text { total }\end{array}$ & $\begin{array}{l}\text { Vínculo } \\
\text { forte }\end{array}$ & $\begin{array}{l}\text { Vínculo } \\
\text { parcial }\end{array}$ & $\begin{array}{l}\text { Vínculo } \\
\text { fraco }\end{array}$ & $\begin{array}{l}\text { Nenhum } \\
\text { vínculo }\end{array}$ \\
\hline $\begin{array}{l}\text { Quanto tempo demoraria para reproduzir este recur- } \\
\text { so em outra parte da organização? }\end{array}$ & $>5$ anos & $2-5$ anos & $6-24$ meses & $1-6$ meses & $<1$ mês \\
\hline $\begin{array}{l}\text { A organização tem um conhecimento explícito dos } \\
\text { fatores necessários para reproduzir este recurso? }\end{array}$ & $\begin{array}{l}\text { De forma } \\
\text { alguma }\end{array}$ & $\begin{array}{l}\text { Muito } \\
\text { pouco }\end{array}$ & Parcialmente & $\begin{array}{l}\text { Em grande } \\
\text { parte }\end{array}$ & $\begin{array}{l}\text { Completa- } \\
\text { mente }\end{array}$ \\
\hline
\end{tabular}

Fonte: Adaptado de MILLS et al., 2002.

números fracionados, adota-se o critério de arredondamento para o menor valor inteiro.

Embora a metodologia utilizada preveja a quantificação na avaliação de recursos, a análise dos resultados globais não incluiu uma avaliação estatística e dependeu basicamente da interpretação dos pesquisadores. Portanto, ainda é possível afirmar que

$$
\frac{\text { Total de questões }(5)}{\text { Total de questões válidas }(n)} \times \begin{aligned}
& \text { Soma da pontuação das } \\
& \text { questões válidas }
\end{aligned}
$$

\section{Resultados}

A cidade na qual as empresas pesquisadas estão situadas conta atualmente com 24 hotéis, a grande maioria de pequeno porte, que se dedicam primordialmente à hospedagem de executivos e profissionais que viajam ao município para a realização de negócios. Embora sejam de pequeno porte, os dois hotéis estudados ocupam uma posição de destaque no setor, motivo pelo qual foram escolhidos para a pesquisa de campo.

Por questões de sigilo, os nomes dos hotéis não serão divulgados neste artigo, sendo utilizadas as seguintes denominações: Hotel 1 e Hotel 2. As informações gerais acerca das empresas podem ser observadas no Quadro 6.
Nas entrevistas realizadas, foi possível identificar o posicionamento estratégico das empresas e reconhecer como os recursos dão suporte às estratégias adotadas. Embora os recursos atuassem de maneiras diferentes para os dois hotéis, um fator que merece destaque é que foram identificados os mesmos recursos para ambos. Isso reforça a ideia de que empresas de um mesmo setor dependem dos mesmos recursos, porém, a capacidade de explorar esses recursos é o que as diferencia.

Para os dois hotéis, foram identificados quatro recursos considerados como estratégicos. Esses recursos são descritos abaixo e categorizados no Quadro 7:

a) Recurso 1: Funcionários - Além da capacitação das pessoas que trabalham na empresa, este recurso se refere também à forma que essas pessoas desempenham suas funções de atendimento ao cliente.

b) Recurso 2: Estrutura física - Este recurso engloba a estrutura geral do Hotel que não faz parte do interior dos apartamentos, incluindo itens como: instalações do prédio, garagem, sala de espera, decoração do ambiente, materiais e equipamentos, dentre outros

c) Recurso 3: Localização - Diz respeito não somente à localização geográfica, mas inclui condições de acesso e mobilidade para os clientes.

d) Recurso 4: Equipamentos dos apartamentos - Este recurso inclui todos os itens 
do apartamento, sejam equipamentos ou materiais.

Após a identificação dos recursos estratégicos, cada um dos recursos foi avaliado em relação ao valor, à sustentabilidade e à versatilidade. 0 procedimento foi feito para todos os recursos dos dois hotéis, sendo registrado nas planilhas desenvolvidas, tal como exemplificam os Quadros 8, 9 e
10 para a avaliação do recurso "Funcionários" do Hotel 1.

Depois da avaliação dos recursos dos dois hotéis, os resultados foram sintetizados no Quadro 11, para que se pudesse ter uma visão global das duas empresas.

As planilhas de avaliação e seus resultados numéricos que definiram o grau de importância de cada recurso foram essenciais para que os gerentes

Quadro 6 - Características gerais dos hotéis pesquisados

\begin{tabular}{|c|c|c|}
\hline Características & Hotel 1 & Hotel 2 \\
\hline Administração & $\begin{array}{l}\text { A administração é centralizada pelo proprie- } \\
\text { tário. }\end{array}$ & $\begin{array}{l}\text { A administração é de natureza familiar e é } \\
\text { realizada em conjunto pelos sócios. }\end{array}$ \\
\hline Acomodações & $\begin{array}{l}\text { O hotel possui } 45 \text { acomodações, entre aparta- } \\
\text { mentos single, executivos e de luxo. }\end{array}$ & $\begin{array}{l}\text { O hotel possui } 121 \text { acomodações, entre apar- } \\
\text { tamentos single, executivos e de luxo. }\end{array}$ \\
\hline Capacidade & Capacidade máxima para 100 hóspedes. & Capacidade máxima para 290 hóspedes. \\
\hline Principais serviços oferecidos & $\begin{array}{l}\text { TV a cabo, ar-condicionado e frigobar nos } \\
\text { quartos, além de estacionamento e serviços de } \\
\text { lavanderia. }\end{array}$ & $\begin{array}{l}\text { Espaço fitness, piscina, bar, lavanderia, sala de } \\
\text { TV, estacionamentos privativos, TV a cabo e } \\
\text { frigobar nos apartamentos. }\end{array}$ \\
\hline Serviços adicionais & $\begin{array}{l}\text { Serviço de reservas online por meio do endere- } \\
\text { ço eletrônico. }\end{array}$ & $\begin{array}{l}\text { Duas salas de convenções com capacidade } \\
\text { para } 150 \text { pessoas, além do serviço de coffee } \\
\text { break e reservas on line, por meio do endereço } \\
\text { eletrônico. }\end{array}$ \\
\hline Nível de serviço & $\begin{array}{l}\text { Menos luxuoso e menor, apresenta um padrão } \\
\text { de estrutura inferior ao do Hotel } 2 \text {. Oferece } \\
\text { serviços essenciais de um hotel. }\end{array}$ & $\begin{array}{l}\text { Mais sofisticado e luxuoso, oferece mais } \\
\text { opções de serviços, como lavanderia própria e } \\
\text { piscina. Serviços mais caros direcionados para } \\
\text { um público de maior poder aquisitivo. }\end{array}$ \\
\hline
\end{tabular}

Fonte: Dados da pesquisa.

Quadro 7 - Recursos identificados

\begin{tabular}{|c|c|c|c|c|c|c|c|c|}
\hline \multirow{2}{*}{ Recursos-Chave } & \multicolumn{4}{|c|}{ Tangíveis } & \multicolumn{4}{|c|}{ Intangíveis } \\
\hline & Instalações & Pessoal & Clientes & Materiais & Informações & Sistemas & Experiência & Relacionamento \\
\hline Funcionários & & $x$ & & & & & $x$ & $x$ \\
\hline Estrutura física & $x$ & & & $x$ & & & & \\
\hline Localização & $x$ & & & & & & & \\
\hline $\begin{array}{l}\text { Equipamentos dos } \\
\text { aptos. }\end{array}$ & $x$ & & & $x$ & & & & \\
\hline
\end{tabular}

Fonte: Dados da pesquisa. 
Quadro 8 - Avaliação do valor do recurso "Funcionários" do Hotel 1

\begin{tabular}{|c|c|c|c|c|c|}
\hline \multirow{2}{*}{ Valor do Recurso } & \multicolumn{5}{|c|}{ Pontuação } \\
\hline & 1 & 2 & 3 & 4 & 5 \\
\hline $\begin{array}{l}\text { Qual é o seu efeito sobre a lucratividade da } \\
\text { organização? }\end{array}$ & $\begin{array}{l}\text { Altamente } \\
\text { negativo }\end{array}$ & $\begin{array}{l}\text { Impacto } \\
\text { negativo }\end{array}$ & $\begin{array}{l}\text { Impacto } \\
\text { nulo }\end{array}$ & $\begin{array}{l}\text { Impacto } \\
\text { positivo }\end{array}$ & $\begin{array}{l}\text { Altamente } \\
\text { positivo }\end{array}$ \\
\hline $\begin{array}{l}\text { Qual é a sua influência para ajudar a empresa a não } \\
\text { ter uma desvantagem competitiva? }\end{array}$ & $\begin{array}{l}\text { Altamente } \\
\text { negativo }\end{array}$ & $\begin{array}{l}\text { Impacto } \\
\text { negativo }\end{array}$ & $\begin{array}{l}\text { Impacto } \\
\text { nulo }\end{array}$ & $\begin{array}{l}\text { Impacto } \\
\text { positivo }\end{array}$ & $\begin{array}{l}\text { Altamente } \\
\text { positivo }\end{array}$ \\
\hline $\begin{array}{l}\text { Qual é a sua influência para ajudar a empresa a } \\
\text { obter uma vantagem competitiva? }\end{array}$ & $\begin{array}{l}\text { Altamente } \\
\text { negativo }\end{array}$ & $\begin{array}{l}\text { Impacto } \\
\text { negativo }\end{array}$ & $\begin{array}{l}\text { Impacto } \\
\text { nulo }\end{array}$ & $\begin{array}{l}\text { Impacto } \\
\text { positivo }\end{array}$ & $\begin{array}{l}\text { Altamente } \\
\text { positivo }\end{array}$ \\
\hline Quantos concorrentes já possuem o mesmo recurso? & Todos & A maioria & Metade & Alguns & Nenhum \\
\hline $\begin{array}{l}\text { Comparado com a concorrência, qual o nível de } \\
\text { qualidade desse recurso? }\end{array}$ & $\begin{array}{l}\text { Muito abai- } \\
\text { xo da média } \\
\text { do setor }\end{array}$ & $\begin{array}{l}\text { Abaixo da } \\
\text { média do } \\
\text { setor }\end{array}$ & $\begin{array}{l}\text { Na média do } \\
\text { setor }\end{array}$ & $\begin{array}{l}\text { No nível dos } \\
\text { melhores }\end{array}$ & $\begin{array}{l}\text { Liderança } \\
\text { inquestio- } \\
\text { nável }\end{array}$ \\
\hline Pontuação total & 20 & ssificação & & & Alto \\
\hline
\end{tabular}

Fonte: Dados da pesquisa.

Quadro 9 - Avaliação da sustentabilidade do recurso "Funcionários" do Hotel 1

\begin{tabular}{|c|c|c|c|c|c|}
\hline \multirow{2}{*}{ Sustentabilidade do Recurso } & \multicolumn{5}{|c|}{ Pontuação } \\
\hline & 1 & 2 & 3 & 4 & 5 \\
\hline $\begin{array}{l}\text { Com que facilidade os concorrentes podem adquirir } \\
\text { este recurso? }\end{array}$ & $\begin{array}{l}\text { Muito facil- } \\
\text { mente }\end{array}$ & $\begin{array}{l}\text { Com certa } \\
\text { facilidade }\end{array}$ & $\begin{array}{l}\text { Com certa } \\
\text { dificuldade }\end{array}$ & Dificilmente & $\begin{array}{l}\text { O recurso é } \\
\text { único }\end{array}$ \\
\hline $\begin{array}{l}\text { Quanto tempo demora para se obter um retorno } \\
\text { financeiro sobre este recurso? }\end{array}$ & $<1$ mês & $\begin{array}{l}1-6 \\
\text { meses }\end{array}$ & $\begin{array}{l}6 \text { - } 24 \\
\text { meses }\end{array}$ & $\begin{array}{l}2-5 \\
\text { anos }\end{array}$ & $>5$ anos \\
\hline $\begin{array}{l}\text { Qual seria o percentual de faturamento para adqui- } \\
\text { rir tal recurso? }\end{array}$ & $<0,5 \%$ & $0,5-1 \%$ & $1-5 \%$ & $5-20 \%$ & $>20 \%$ \\
\hline Qual a taxa de depreciação desse recurso? & $\begin{array}{l}\text { Não apli- } \\
\text { cável }\end{array}$ & & & & \\
\hline $\begin{array}{l}\text { Sua vantagem pode ser substituída por outro } \\
\text { recurso? }\end{array}$ & $\begin{array}{l}\text { Completa- } \\
\text { mente }\end{array}$ & $\begin{array}{l}\text { Em grande } \\
\text { parte }\end{array}$ & Parcialmente & Dificilmente & $\begin{array}{l}\text { De forma } \\
\text { alguma }\end{array}$ \\
\hline Pontuação total & $17,5 \approx 17$ & ssificação & & & Média \\
\hline
\end{tabular}

Fonte: Dados da pesquisa.

dos hotéis e os pesquisadores tivessem condições de refletir sobre as estratégias de desenvolvimento, manutenção e retenção de recursos estratégicos que poderiam ser empreendidas. Os motivos que levaram os hotéis a receberem tais avaliações são discutidos na próxima seção.

\section{Discussão}

Ao analisar os resultados das avaliações, é necessário ressaltar que as mesmas refletem as percepções dos entrevistados sobre os seus recursos estratégicos. Mesmo que os pesquisadores fossem 
responsáveis por conduzir as entrevistas, evitando distorções de avaliação, a opinião dos entrevistados ainda era um fator de influência preponderante nos resultados. Como os estudos de caso não tinham um caráter comparativo entre as duas empresas, optou-se por manter a avaliação fiel às respostas dos entrevistados, embora se percebessem diferenças sutis entre a situação real e a percebida.

A avaliação do valor dos recursos, por exemplo, refletiu as prioridades estratégicas e a autocrítica dos entrevistados. Em relação ao recurso "Equipamentos dos apartamentos", o Hotel 1 recebeu uma avaliação melhor do que o Hotel 2, embora a percepção dos pesquisadores fosse exatamente o contrário disso. Esse ponto chamou a atenção para outra questão: os dois hotéis não focalizam o mesmo público-alvo e, portanto, não são concorrentes diretos. Como a avaliação dos recursos, principalmente em relação aos critérios de valor e sustentabilidade, é consequência da situação de cada recurso em comparação com a concorrência, os resultados demonstram a importância do recurso para o contexto de cada empresa, tendo em vista seu segmento de atuação. Por esse motivo, é possível afirmar que as aparentes distorções de avaliação não são significativas, sendo que os resultados são confiáveis para cada empresa, sem esperar que os dois hotéis possam ser comparados. Comparações à parte, é importante destacar que a metodologia de avaliação traz uma grande contribuição para a própria empresa, possibilitando que a mesma tenha condições objetivas de

Quadro 10 - Avaliação da versatilidade do recurso "Funcionários" do Hotel 1

\begin{tabular}{|c|c|c|c|c|c|}
\hline \multirow{2}{*}{ Versatilidade do Recurso } & \multicolumn{5}{|c|}{ Pontuação } \\
\hline & 1 & 2 & 3 & 4 & 5 \\
\hline $\begin{array}{l}\text { O recurso pode ser transferido para outros serviços } \\
\text { e unidades da empresa? }\end{array}$ & Impossível & $\begin{array}{l}\text { Com dificul- } \\
\text { dade }\end{array}$ & $\begin{array}{l}\text { Com algum } \\
\text { esforço }\end{array}$ & Facilmente & $\begin{array}{l}\text { Muito facil- } \\
\text { mente }\end{array}$ \\
\hline $\begin{array}{l}\text { Este recurso depende de recursos e/ou processos } \\
\text { complementares para ser transferido? }\end{array}$ & $\begin{array}{l}\text { Completa- } \\
\text {-mente }\end{array}$ & $\begin{array}{l}\text { Depende } \\
\text { bastante }\end{array}$ & $\begin{array}{l}\text { Parcialmen- } \\
\text { te }\end{array}$ & $\begin{array}{l}\text { Depende } \\
\text { pouco }\end{array}$ & $\begin{array}{l}\text { Indepen- } \\
\text { dente }\end{array}$ \\
\hline $\begin{array}{l}\text { Este recurso está vinculado a alguma região geo- } \\
\text { gráfica? }\end{array}$ & $\begin{array}{l}\text { Vínculo } \\
\text { total }\end{array}$ & $\begin{array}{l}\text { Vínculo } \\
\text { forte }\end{array}$ & $\begin{array}{l}\text { Vínculo } \\
\text { parcial }\end{array}$ & $\begin{array}{l}\text { Vínculo } \\
\text { fraco }\end{array}$ & $\begin{array}{l}\text { Nenhum } \\
\text { vínculo }\end{array}$ \\
\hline $\begin{array}{l}\text { Quanto tempo demoraria para reproduzir este recurso } \\
\text { em outra parte da organização? }\end{array}$ & $>5$ anos & $2-5$ anos & $6-24$ meses & $1-6$ meses & $<1$ mês \\
\hline $\begin{array}{l}\text { A organização tem um conhecimento explícito dos } \\
\text { fatores necessários para reproduzir este recurso? }\end{array}$ & $\begin{array}{l}\text { De forma } \\
\text { alguma }\end{array}$ & $\begin{array}{l}\text { Muito } \\
\text { pouco }\end{array}$ & Parcialmente & $\begin{array}{l}\text { Em grande } \\
\text { parte }\end{array}$ & $\begin{array}{l}\text { Completa- } \\
\text { mente }\end{array}$ \\
\hline Pontuação total & 16 & ssificação & & & Média \\
\hline
\end{tabular}

Fonte: Dados da pesquisa.

Quadro 11 - Síntese da avaliação de recursos para os dois hotéis

\begin{tabular}{lcccccc}
\hline \multirow{2}{*}{ RECURSOS } & \multicolumn{2}{c}{ VALOR } & SUSTENTABILIDADE & & VERSATILIDADE \\
\cline { 2 - 7 } & HOTEL 1 & HOTEL 2 & HOTEL 1 & HOTEL 2 & HOTEL 1 & HOTEL 2 \\
\hline Funcionários & Alto & Muito alto & Média & Alta & Média & Média \\
Estrutura Física & Muito alto & Muito alto & Muito alta & Muito alta & Alta & Média \\
Localização & Alto & Alto & Alta & Muito alta & Alta & Alta \\
Equip. dos aptos & Muito alto & Médio & Alta & Alta & Alta & Alta \\
\hline
\end{tabular}

Fonte: Dados da pesquisa. 
definir prioridades de desenvolvimento de recursos estratégicos.

Os dois hotéis justificaram a alta sustentabilidade dos recursos "Estrutura física" e "Equipamentos dos apartamentos" pelo alto investimento que fizeram, o que de fato representa uma barreira à entrada de novos concorrentes. Entretanto, assim como na avaliação do valor dos recursos, é preciso relativizar a avaliação e projetar um cenário de futuras alterações no contexto competitivo. A recente implantação de um novo hotel na cidade, pertencente a uma grande rede de hotelaria, começou a trazer mudanças para a estrutura competitiva do setor. Embora o alto capital investido ainda seja uma barreira de entrada para a maioria das empresas do setor, que via de regra são de pequeno porte e de propriedade familiar, definitivamente não representa uma barreira tão significativa para hotéis que pertencem a grandes grupos empresariais. Portanto, quando se amplia o contexto de análise, o nível de sustentabilidade dos dois hotéis tende a cair.

Os entrevistados dos dois hotéis reconheceram que o recurso "Funcionários" exercia um alto impacto para sua estratégia, servindo inclusive como um elemento que ajuda a tirar um melhor proveito dos outros recursos estratégicos. No entanto, somente o Hotel 2 demonstrou uma estratégia clara de desenvolvimento desse recurso. De acordo com o proprietário do Hotel 2, o alto nível desse recurso permite ao hotel oferecer um diferencial de flexibilidade e relacionamento mais próximo com o cliente, fator que foi observado na pesquisa. Esse fator diferencial ajuda a proteger a empresa da concorrência de hotéis de grandes redes, que geralmente oferecem serviços mais padronizados e impessoais.

De uma forma geral, os dois hotéis estão bem posicionados em seus nichos de atuação. Porém, ao analisar sua estratégia pela ótica da visão baseada em recursos, os gerentes dessas empresas passariam a prestar mais atenção a seus recursos estratégicos, desenvolvendo uma blindagem contra seus concorrentes e explorando estratégias de crescimento apoiadas em suas competências.

\section{Considerações finais}

A visão baseada em recursos traz uma perspectiva diferente para o modo de pensar a estratégia empresarial. Uma área acadêmica que foi originada por uma visão estritamente orientada pelo mercado e pela concorrência ainda carece de um equilíbrio maior e do reconhecimento de que são os recursos empresariais os verdadeiros responsáveis por viabilizar a estratégia. No entanto, mesmo que a RBV aos poucos venha ocupando um espaço maior na literatura acadêmica e empresarial, a sua operacionalização ainda é difícil e seus conceitos ainda parecem um tanto vagos quando se busca uma aplicação.

Nesse sentido, uma das contribuições desse artigo é a proposta de uma metodologia prática e de fácil utilização que permite avaliar recursos estratégicos de forma objetiva em pesquisas de cunho científico ou nos processos de gestão estratégica das empresas. Construída com base nas metodologias existentes, notadamente a de Mills et al. (2002), a metodologia proposta vai além da ferramenta que lhe deu origem, com a possibilidade de atribuir uma pontuação que dá a noção quantificável do grau de importância de cada recurso.

Do ponto de vista acadêmico, a análise de recursos estratégicos nos hotéis pesquisados confirmou a aplicabilidade da metodologia proposta. Do ponto de vista empresarial, a pesquisa trouxe luz a assuntos que não eram discutidos nas empresas pesquisadas, mas que, a partir dos resultados revelados, direcionam o foco da gestão estratégica dessas empresas. Embora os hotéis ocupassem posições de destaque no setor, a visão baseada em recursos apresentou uma perspectiva nova e de longo prazo para eles, em busca do incremento do valor, da sustentabilidade e da versatilidade de seus recursos estratégicos.

A aplicação da metodologia permitiu identificar as contingências e as restrições da análise de recursos estratégicos em empresas reais, nos casos relatados nesse artigo, em empresas do setor hoteleiro. Uma das restrições foi a dependência da avaliação na percepção dos entrevistados. Esse fator pode ser amenizado com a diversificação de fontes e técnicas de coleta de dados, possibilitando a triangulação entre as informações pesquisadas. Mantendo a opção pelo método do estudo de caso, pode-se complementar a coleta de dados com uso de grupos focais, que acabam gerando uma avaliação por consenso. Outra opção é adotar o método da pesquisa-ação, que envolve os sujeitos da pesquisa e os compromete com o resultado da avaliação de recursos.

Além da diversificação de métodos e técnicas de investigação, a pesquisa pode ser ampliada com a inclusão do cliente como um contraponto para a avaliação 
de recursos estratégicos. Especialmente em relação ao critério "valor", é importante que se tenha uma visão de como o mercado avalia os recursos que são considerados importantes para as empresas. A pesquisa com os clientes poderia inclusive sinalizar recursos estratégicos que não foram identificados pelas empresas. Do mesmo modo, a pesquisa poderia analisar a concorrência com mais profundidade, considerando que o grau de importância de um recurso sempre é determinado com base nesse parâmetro implícito.

\section{Referências}

AREND, R. J.; LÉVESQUE, M. Is the resource-based view a practical organizational theory? Organization Science, v. 21, n. 4, p. 913-930, 2010.

ARMISTEAD, C. G.; CLARK, G. Resource activity mapping: the value chain in service operations strategy. The Service Industries Journal, v. 13, n. 4, p. 221-239, 1993.

BARNEY, J. B. Is the resource based "view" a useful perspective for strategic management research? Yes. Academy of Management Review, v. 26, n. 1, p. 41-56, 2001.

BARNEY, J. B.; HESTERLY, W. S. Administração estratégica e vantagem competitiva. São Paulo: Pearson Prentice Hall, 2007.

BESANKO, D. et al. A economia da estratégia. 3. ed. Porto Alegre: Bookman, 2006.

COATES, T. T.; McDERMOTT, C. M. An exploratory analysis of new competencies: a resource based view perspective. Journal of Operations Management, v. 20, n. 5, p. 435450, 2002.

ESCRIG-TENA, A. B.; BOU-LLUSAR, J. C. A model for evaluating organizational competencies: an application in the context of a quality management initiative. Decision Sciences, v. 36, n. 2, p. 221-257, 2005.

GRANT, R. M. The resource-based theory of competitive advantage: implications for strategy formulation. California Management Review, v. 33, n. 3, p. 114-135, 1991.

GRUBER, M. et al. Configurations of resources and capabilities and their performance implications: an exploratory study on technology ventures. Strategic Management Journal, v. 31, n. 12, p. 1337-1356, 2010.
KUNC, M. H.; MORECROFT, J. D. W. Managerial decision making and firm performance under a resource-based paradigm. Strategic Management Journal, v. 31, n. 11, p. 1164-1182, 2010.

LEWIS, M. A. Analysing organisational competence: implications for the management of operations. International Journal of Operations \& Production Management, v. 23, n. 7, p. 731-756, 2003.

MEDCOF, J. W. Resource-based strategy and managerial power in networks of internationally dispersed technology units. Strategic Management Journal, v. 22, n. 11, p. 999-1012, 2001.

MILLS, J. et al. Competing through competences. Cambridge, UK: Cambridge University Press, 2002.

MILLS, J.; PLATTS, K.; BOURNE, M. Applying resource-based theory: methods, outcomes and utility for managers. International Journal of Operations \& Production Management, v. 23, n. 2, p. 148-166, 2003.

NIEWEGLOWSKI, R.; LIMA, E. P.; COSTA, S. E. G. Desenvolvendo um processo de análise de investimentos baseado em competências. Gestão \& Produção, v. 17, n. 2, p. 317-337, 2010.

PANDŽA, K. et al. Evolutionary perspectives on the capability accumulation process. International Journal of Operations \& Production Management, v. 23, n. 8, p. 822-849, 2003.

PENG, D. X.; SCHROEDER, R. G.; SHAH, R. Linking routines to operations capabilities: a new perspective. Journal of Operations Management, v. 26, n. 6, p. 730-748, 2008.

PENROSE, E. T. The theory of the growth of the firm. Oxford: Oxford University Press, 1968.

PETERAF, M. A. The cornerstones of competitive advantage: a resource-based view. Strategic Management Journal, v. 14, n. 3, p. 179-191, 1993.

PRAHALAD, C. K.; HAMEL, G. The core competence of the corporation. Harvard Business Review, v. 68, n. 3, p. 7991, 1990

SLACK, N.; LEWIS, M. Estratégia de operações. 2. ed. Porto Alegre: Bookman, 2009.

WERNERFELT, B. A resource-based view of the firm. Strategic Management Journal, v. 5, n. 2, p. 171-180, 1984. 
WONG, C. Y.; KARIA, N. Explaining the competitive advantage of logistics service providers: a resource-based view approach. International Journal of Production Economics, v. 128, n. 1 , p. $51-67,2010$.

YANG, B. et al. On establishing the core competency identifying model: a value-activity and process oriented approach. Industrial Management \& Data Systems, v. 106, n. 1 , p. $60-80,2006$.
YIN, R. K. Case study research: design and methods. 2nd ed. Thousand Oaks: Sage, 1994.
Recebido: 26/09/2011

Received: 09/26/2011

Aprovado: $18 / 10 / 2011$

Approved: 10/18/2011 